\title{
Lecture
}

\section{Psychiatry and Realism}

\author{
The Freudenberg Lecture, 1987*
}

Donal F. Early, Emeritus Consultant Psychiatrist, 7 Percival Road, Clifton, Bristol

In preparing this talk I rapidly looked through some of the Departmental documents in the last ten years, mainly those which have been issued since I retired from the NHS in 1979. I looked at Organisational and Management Problems of Mental Illness Hospitals-The Nodder Report, which was strangled at birth; at Patients First (1979) in which Patrick Jenkin claimed that "The first objective of the 1974 reorganisation, the integration of services for patients in the hospital and in the community has been substantially achieved"; at Gerard Vaughan's Future Pattern of Hospital Provision in England (May 1980) in which he said; "It will often not be possible to close large and unsuitable long-stay hospitals unless some or all of the services could be provided elsewhere ... in the 70 or so districts which have a well sited mental hospital this will usually have to continue to provide all hospital in-patient care and be the focus for many years to come"; at Care in Action (February 1981) in which Patrick Jenkin admitted that "It appears that increases in provisions since 1975 have not been geared directly to providing a genuine alternative for those on the margins of institutional care ... other objectives of community service ... considered more important"; at Norman Fowler's Care in the Community (July 1982) to which the College responded "... we believe that failure to provide community services for the past 20 years is not purely due to lack of finance in local authorities but is due to reluctance by many local authorities to accept that they should have responsibility for a significant number of mentally ill and mentally handicapped"; at Kenneth Clark's New Initiatives in the Community (March 1983) which kept up the pressure to discharge hospital patients by enabling health authorities to offer local authorities and voluntary organisations indefinitely continuing payments to provide patient care. And on and on the machine churns out advice and instructions with increasing pressure as Griffith's management progresses

*The Lecture was given at the Freudenberg Postgraduate Medical Centre, Netherne Hospital, Coulsdon, Surrey on 27 May 1987. Dr Freudenberg's Obituary appeared in the Bulletin. November 1983. 7, 215 . until Griffith himself was asked in November 1986 " to review the way in which the public funds are used to support the community care policy and to advise me (Norman Fowler) on the options that would improve the use of these funds as a contribution to more effective community care". By Mrs Currie's reply on the same date (27 November 1986) one would think that we have arrived at Utopia: "Local authority residential accommodation nearly 6,000 ; nearly 18,000 day hospital and day centre places increased to nearly 9,000 " for the mentally ill. But disquieting reports continue to suggest that the quality of care in many hostels is no better than in the hospitals from which patients have "escaped" (Leader in the Guardian newspaper, 10 February 1978) and that the danger of hostels becoming as institutionalised as hospitals is very great. I have a vast collection of cuttings from local newspapers, e.g. on 5 January 1987 it was reported that there are now 20,000 homeless people in Bristol and that "a significant number (of these) are people suffering from mental health problems who at some time have been in mental hospitals". It was reported that "people with mental health problems ended up sleeping rough" because of failure to confront the problem. The Cyrenians (Evening Post, 20 January 1987) reported that "the numbers of mentally ill coming to us are also growing because of the new community care programme".

Marjorie Wallace writing in the Sunday Times magazine on 3 May 1987 (A Caring Community) describes as what she refers to "the plight of Britain's mentally ill" with passion and conviction introducing her article thus: "It was a startling idea; to release the mentally ill from asylums and put them back into the mainstream of life, into a caring community. It was a plan born out of compassion, optimism and the discovery of new drugs which controlled some of the most crippling mental disorders. It started 25 years ago and it has been pursued as a policy by every government since. At first it worked. But now 25 years later the optimism has run dry, the compassion looks threadbare and in too many instances the forces of commercialism are all that is being brought to bear upon the problem of progressively sicker people as they are uprooted. So far 60,000 patients have been returned to the community and more continue to 
be.... For many people, as our investigation shows, the concept of a caring community is a sick joke".

Miss Wallace, accompanied by Lord Snowdon as her photographer, visited Southsea, Southport, Lincoln, Liverpool, Yeovil and London. They concluded "The brochure language of community care enthusiasts does not reflect what we saw, a few in model schemes, others in neglected sort of independence in flats and bedsits, many at home destroying not only their lives but those of their families around them. The rest were in bed \& breakfast, dismal lodging houses, night shelters, on the streets".

The article should be read in full. Taken in conjunction with Esther Rantzen's equally critical assessment in 'That's Life' on Sunday, 24 May 1987, it emphasises the fact that we professionals cannot go on indefinitely blinkered from reality as others see it . We know that the problems exist, we encounter them daily but we have not sufficiently raised our voices. We have seen the international television film 'The Forgotten Millions' and we understand or should understand how split authorities enable each authority to leave responsibility to the other. Do we really want night shelters like New York? "The State failed to assess just what would be available to patients if discharged. They released them before there were adequate community facilities.... The policy of deinstitutionalisation has had a devastating effect upon the City", said Dr Kellerman, Commissioner of Mental Health, New York City in January 1981.

No preliminary work was done here, except the feasibility study of Powick, and Kathleen Jones knows of no major study which has followed up the welfare of discharged patients, nor whether the patients and relatives prefer the community to hospital care, not in the United States, not in Italy, not in Scandinavia. But we as a profession have protested little when the Social Services Secretary authorised the Health Authorities to pay managers bonuses of up to $£ 3,960$ according to the "extent of changes" they are expected to achieve in the NHS, including hospital closures. "Substantial closures" are necessary, according to the circular, to win the bonuses of $£ 1,660$ per annum for regional managers $(5 \%), £ 3,160$ for district managers $(10 \%)$, and $£ 3,900$ for unit managers-people in charge of individual hospitals (15\% of annual salary). Small wonder that there is such a scramble to reduce beds? One manager interviewed by Marjorie Wallace could not bear the sound of his actions and referred to discharge as "normalisation", to ward closure as "rationalisation" and to suicide as "untoward death". "All we are doing is a relocation exercise" he said, but Miss Wallace said that one after another relatives related stories of neglect, loneliness and terror. The Department of Health keeps no record of those who have left the institutions and Miss Wallace points out that it is easy to lose them, they move around the country, homeless, unable even to register with a general practitioner. They disappear between the boundaries of health areas and local authorities.

Emlyn Jones, Director of the National Association of Voluntary Hostels says: "The new managers don't know or care about the failures who come to us. They are creating new ghettos for the mentally ill." Time and again one hears, "Once they are discharged it is difficult to get help. Once the social worker has delivered them by car that's it; just dropped on my doorstep", and according to many in the non-statutory sector it is getting worse.

I believe that this long introductory preamble is necessary to highlight the plight of community psychiatry of the late 1980 s. For over 35 years we have worked towards the ideal of extra-hospital care. In 1960 Brian Cooper and I demonstrated that there were 380 patients in the (then) Bristol Mental Hospital who were not in need of hospital treatment and we advised the Medical Officer of Health for Bristol that he could immediately plan hostel accommodation for 60 clients which could be immediately filled by discharges from hospital.

In the same hospital survey we opined that daytime occupation was an essential part of resocialisation and in 1957 we established industrial therapy in hospital. In 1960 the Industrial Therapy Organisation (Bristol) Ltd (ITO) began its work. It is unfortunate that occupational therapists and doctors were unable to develop this approach more vigorously and that they were able to use the slump of the seventies as an excuse to retire almost completely from the field. Industry is certainly not what it was but it still represents the most realistic approach to occupation and resocialisation. In a recent leader in the British Medical Journal, Smith has reviewed some of the changes currently taking place and how the trend has moved from 40 hours for 40 weeks for 40 years to 35 hours for 35 weeks for 35 years. Whatever the trend and however little or what work there is, we are entitled to our share of it.

In the interest of realism I would like to share some of our experiences with the industry. In 1985 ITO celebrated its 25th anniversary. Its pattern of activity and its profile has changed markedly in this time. There have been 1,500 referrals. During the first five years they ran at 100 p.a., to 75 p.a. in the second five years and since 1975 at about 50 p.a. Initially the majority of referrals came from Glenside Hospital where the chronic population has fallen from 1000 in 1960 to 368 in 1985. The referral rate from this hospital has fallen from $62 \%$ to $14 \%$. The local authority, other psychiatric sources and the Manpower Services Commission have taken over. In the first three quinquennia the predominant diagnosis was schizophrenia, in the fourth affective illness and from 1980 intellectual impairment has predominated. All categories of psychiatric illness have been referred and accepted. Through each five year period the 30 to 50 age group has been the largest (overwhelmingly unmarried). In 25 years $371(26 \%)$ have been settled in open industry, $219(15 \%)$ in sheltered work, i.e. $41 \%$ of all referrals have become wage earners. The numbers of referrals have diminished but number attending remains high. On 31 December 1985 there were 124 workers on the books of ITO.

ITO has been largely self-supporting. In 1960 an outside factory facilitated the then apparently insurmountable leap out of hospital. A contract factory staffed by hospital nurses and by supervisors from outside industry and supported 
by the goodwill of an enlightened Hospital Management Committee enabled an otherwise unsupported voluntary organisation to progress patients from hospital to community. Free from bureaucratic control, it took three months from conception to operation from December 1959 to March 1960. ITO is in a sound financial and industrial condition and continues to provide a day to day service to psychiatric patients.

And so the wheel turns its full circle-a job to do and a place to live. In 1987 the Bristol Industrial Therapy Housing Association (BITHA) was 25 years old and has been incorporated into the Industrial Therapy Organisation (whereas previously it was an independent housing association). The organisation grew out of the failure of the local authority to provide accommodation for patients industrially rehabilitated through ITO. For a patient to be accepted for a Sheltered Industrial Group (1962) it was necessary to assure the (then) Ministry of Labour that he/she would be discharged within the forseeable future. ITO had the industrial potential. The 'community' did not have the resettlement ability so BITHA was formed.

The Association has now three hotels and six houses and provides accommodation for 74 residents. In May 1976, we proposed the building of no-frill accommodation financed by Barbara Castle's recently introduced joint planning arrangements. Our architects designed a campus of 50 places to cost between $£ 130,000$ and $£ 140,000$, which the Bristol Industrial Housing Association offered to run on the lines of its established houses and hotels. The project is described in the report of the Annual General Meeting of the National Association for Mental Health (MIND) 1977 as serving the purposes of training, of trial and of demonstration of abilities of discharged hospital patients and of indicating their social needs. The scheme was commercially viable but failed to attract joint planning funds.

In 1978 BITHA was offered funds by the Housing Corporation to provide a modified scheme which maintained all the essential features of the first plan. The Chief Regional Officer of the Housing Corporation wrote: “... how interested and impressed we were with the pioneering work that BITHA has clearly been undertaking in the field of community care for ex-psychiatric patients ... your organisation .... appreciated the importance of this field long before it became fashionable to espouse it and more importantly you have been able to put many of your ideas into practice". The Area Medical Officer opposed the revised plan on the grounds that it was now a housing development and would have to be renegotiated as a new project. The Health District Officers and the Director of Social Services also denied support although the Director wrote that he would not oppose the plan but "would express reservations to anyone who consulted him"! Negotiations started again from scratch. The plan was approved in principle by the District Team, as was agreement to convey the site. Negotiations passed into the hands of the Housing Corporation and the Hospital Authorities; ITO heard nothing until the District Administrator wrote on 20 October 1982 that "the Authority does not wish to proceed with the Housing Scheme ... this decision is the view of the people working at Glenside Hospital as well as the District Management Team and the Chairman of the Authority". The decision came six years and nine months after the initial proposal and four years from the offer of the Housing Corporation.

All this sounds very gloomy but there may be a positive side. On 25 April 1987, at the Spring Meeting of the South West Regional Meeting of the College in Bath, Dr James Birley, President of the College, spoke on 'Alternatives to Asylums'. Whilst he agreed that he had little new to say, his approach is encouraging, particularly in that there is a College President who will give some priority during his Presidency to the care and treatment of the chronic patient. Of course, I was heartened by Renée Short's Report but not by its reception by the Government. The Audit Commission Review in December 1986 took as its theme 'Making a reality of community care' and starkly demonstrated that "progress has been slowest for the mentally ill". The concensus statement on 'Caring for the Mentally Disordered in our Communities', prepared at a meeting held at the College on 2 April 1987, is as useful as such a document can be. The manner of its presentation is unlikely to stir politicians to action. Neither will the King's Fund consensus statement which emanated from a conference on 'The need for asylum in society, for the mentally ill or infirm'. At least it was agreed that there is "an enduring body of disordered people with a need for care", and that the development of replacement local services concurrently with hospital closures is critical in maintaining the confidence of recipients, carers and professionals. The conclusion that "an overhaul of current arrangements would often lead to a better use of scarce resources", might seem to lack the necessary urgency!

But when all the professional contributions have been considered, it is the laymen that stir the blood-Marjorie Wallace and Esther Rantzen. I was excited, too, by 'John Burrell explains to Ann Shearer' in the Guardian's Society Tomorrow on 18 March 1987, and on receiving Burrell Foley Associates brochure on 'The Psychiatric Hospital as a Community ... Alternatives in the institution: design for a sane environment'. It is pressures such as these which have prevailed in persuading Norman Fowler to ask Sir Roy Griffiths, the Government's adviser on the Health Service, to undertake an overview of community policy (Hansard, 16 December 1986). 